\title{
Association between vitamin content, plant morphology and geographical origin in a worldwide collection of the orphan crop Gynandropsis gynandra (Cleomaceae)
}

\author{
E. O. Dêêdi Sogbohossou ${ }^{1,2} \cdot$ Dieke Kortekaas $^{1} \cdot$ Enoch G. Achigan-Dako ${ }^{2} \cdot$ Patrick Maundu $^{3} \cdot$ Tsvetelina Stoilova $^{4}$. \\ Allen Van Deynze ${ }^{5} \cdot$ Ric C. H. de $\operatorname{Vos}^{6} \cdot$ M. Eric Schranz ${ }^{1}$ (i)
}

Received: 10 October 2018 / Accepted: 15 March 2019 / Published online: 25 March 2019

(c) The Author(s) 2019

\begin{abstract}
Main conclusion The variability in nutrient content and morphology in Gynandropsis gynandra is associated with the geographic origin of the accessions and provides a basis for breeding for higher levels of vitamin $\mathrm{C}$, carotenoids or tocopherols in higher-yielding cultivars.
\end{abstract}

We examined the variation in carotenoids, tocopherols and ascorbic acid as well as morphological traits in a worldwide germplasm of 76 accessions of the orphan leafy vegetable Gynandropsis gynandra (Cleomaceae) using greenhouse experiments and high-performance liquid chromatography analysis. The levels of carotenoids and tocopherols accumulating in the leaves varied significantly across accessions and were linked with the geographical origin and morphological variation. The main carotenoids included lutein, $\beta$-carotene, $\alpha$-carotene and violaxanthin. A twofold to threefold variation was observed for these compounds. The main tocopherols detected were $\alpha$-tocopherol and $\gamma$-tocopherol with a 20 -fold variation. A ninefold variation in vitamin $\mathrm{C}$ concentration and independent of geographical origin was observed. Overall, the accessions were grouped into three clusters based on variation in nutrient content and morphology. West African accessions were short plants with small leaves and with high tocopherol contents and relatively low carotenoid contents, Asian accessions were short plants with broad leaves and with relatively low carotenoid and high tocopherol contents, while East-Southern African plants were tall with high contents of both carotenoids and chlorophylls and low tocopherol contents. Carotenoids were positively correlated with plant height as well as foliar and floral traits but negatively correlated with tocopherols. The absence of a significant correlation between vitamin $\mathrm{C}$ and other traits indicated that breeding for high carotenoids or tocopherols content may be coupled with improved leaf yield and vitamin $\mathrm{C}$ content. Our study provides baseline information on the natural variation available for traits of interest for breeding for enhanced crop yield and nutrient content in Gynandropsis gynandra.

Keywords Gynandropsis gynandra $\cdot$ Leafy vegetable $\cdot$ Vitamins $\cdot$ Morphology $\cdot$ Natural variation $\cdot$ Geography

Electronic supplementary material The online version of this article (https://doi.org/10.1007/s00425-019-03142-1) contains supplementary material, which is available to authorized users.

M. Eric Schranz

eric.schranz@wur.nl

1 Biosystematics Group, Wageningen University, Droevendaalsesteeg 1, 6708 PB Wageningen, The Netherlands

2 Laboratory of Genetics, Horticulture and Seed Science, Faculty of Agronomic Sciences, University of Abomey-Calavi, BP 2549 Abomey-Calavi, Republic of Benin
3 Kenya Resource Center for Indigenous Knowledge (KENRIK), Centre for Biodiversity, National Museums of Kenya, Museum Hill, P.O. Box 40658, Nairobi 00100, Kenya

4 World Vegetable Center (AVRDC), P.O. Box 42, Shanhua, Tainan 74199, Taiwan

5 Department of Plant Sciences, University of California, Davis 95616, USA

6 Bioscience, Wageningen Plant Research, Wageningen UR, Droevendaalsesteeg 1, 6708 PB Wageningen, The Netherlands 


\section{Introduction}

Tropical areas of the world are endowed with a rich diversity of edible plant species with tremendous potential to contribute to food security, human health and poverty alleviation (Cullis and Kunert 2017; Pinela et al. 2017). However, most of those species are niche or orphan crops with a regional or local importance and often overlooked in breeding programmes (Sogbohossou et al. 2018). With the recent impetus for improved food quality, there is an increasing interest in diet diversification and breeding for highly nutritious crop cultivars. A critical step of this process is to understand the natural variation in phytochemical profiles in the crop of interest. Plant species with broad geographic distributions experience a wide range of biotic and abiotic conditions which thus can drive the evolution of variation in morphology, phytochemical profiles and interactions with other organisms (Millett et al. 2018). A broad sampling of accessions representative of the distribution and environment of the crop is important for maximizing the potential morphological and chemical (nutritional content) variation. Broad diversity is also needed to understand the potential genetic and environmental effects on the observed phenotypes. Such wide-scale studies are particularly critical for emerging orphan crops which have an untapped potential for improved human nutrition and health. Orphan vegetables are particularly important for local communities as they can easily be cultivated yearround and are affordable sources of nutrients (Yang and Keding 2009). Moreover, they substantially contribute to local economies. For example, in sub-Saharan Africa, the market of indigenous vegetables is worth billions of USD (Weinberger and Pichop 2009). Unfortunately, most studies that analyse the nutritional value of these species often focus only on local germplasm collections (Kengni et al. 2003; Kumssa et al. 2017).

Gynandropsis gynandra (syn. Cleome gynandra) is an orphan leafy vegetable belonging to the Cleomaceae family, the sister family to Brassicaceae. The species is a $\mathrm{C}_{4}$ plant that is widespread in tropical areas of the world (van den Bergh et al. 2014). In several communities in Africa and Asia, the plant is harvested in the wild or cultivated in home gardens. Leaves, young shoots and occasionally flowers are eaten boiled in sauces or stews, but leaves can also be blanched and dried for preservation (Flyman and Afolayan 2006; van Den Heever and Venter 2007). There is an increasing awareness of the health benefits of the regular consumption of indigenous leafy vegetables which is enhanced by their availability and affordability. Thus, G. gynandra and other orphan leafy vegetables are increasingly cultivated and sold in urban areas of several African countries. To keep pace with the growing demand in these vegetables, value chain development for these species should go together with breeding efforts. Providing farmers with high-yielding and nutritious leafy vegetable cultivars which meet consumers' requirements is therefore an overriding challenge for breeders (Sogbohossou et al. 2018).

Important nutrients in orphan leafy vegetables that can be improved and bred for include carotenoids (pro-vitamin A), tocopherols (vitamin E) and ascorbic acid (vitamin C). Carotenoids and some of their metabolites play a protective role in many reactive oxygen species (ROS)-mediated disorders, such as cardiovascular diseases, several types of cancer and neurological, photosensitive or eye-related disorders (Fiedor and Burda 2014). Tocopherols have vitamin E activity in mammals, with $\alpha$-tocopherol and $\gamma$-tocopherol exhibiting the greatest effects. These activities involve protecting membrane lipids from ROS damage, acting as antiinflammatory agents, and protecting against degenerative diseases (Miyazawa et al. 2011; Usoro and Mousa 2010). The intake of vitamin $\mathrm{E}$ is generally low and very similar in both developing and industrialized countries (Jiang 2014). Ascorbic acid plays a critical role in cancer treatment, the prevention and/or therapy of asthma, allergic rhinitis, atopic dermatitis, cardiovascular diseases, obesity, neurodegenerative diseases, hypertension and autoimmune diseases (Combs Jr and McClung 2017). For improving crops such as G. gynandra, it is important to establish their nutritional qualities and variation in these and other morphological traits in a broad collection of germplasm.

Previous studies have demonstrated that individual accessions of Gynandropsis gynandra leaves are rich in nutrients including carotenoids, vitamin $\mathrm{C}$ and minerals (Neugart et al. 2017; Odhav et al. 2007; Omondi et al. 2017; Schönfeldt and Pretorius 2011; Uusiku et al. 2010; van Jaarsveld et al. 2014). Variation between accessions of G. gynandra originating from East and Southern Africa showed variations in mineral levels and various health-related compounds including vitamin $\mathrm{C}$, flavonoids, phenolics and glucosinolates, as well as in morphological traits (Jiménez-Aguilar and Grusak 2015; Omondi et al. 2017). A more extensive set of morphological characters of germplasm from Asia and East-Southern Africa at the World Vegetable Center revealed geographical patterns of variation (Wu et al. 2017). A set of nine accessions of G. gynandra from East Africa, West Africa and Asia was used to analyse variation in $\mathrm{C}_{4}$ photosynthesis-related traits coupled with a phylogenetic analysis based on sequences of the internal transcribed spacer region and demonstrated trait variation that clustered according to geographical origin. The accessions from Asia and West Africa were more closely related to each other than with East African accessions (Reeves et al. 2018).

The aim of the present study was to investigate the natural variation in morphological features and nutrient content 
within G. gynandra to provide baseline information for multiple trait breeding strategies. The plant material used included 76 accessions that cover a wider geographic distribution than the aforementioned studies, including accessions from West Africa, East and Southern Africa as well as Asia. By targeted nutrient analysis, we investigated the variation in carotenoids, tocopherols and ascorbic acid and their association with morphological variation. We specifically address the following questions: What is the extent of variation in morphological traits and levels of nutrients in the collection? Is there a relationship between the morphological characteristics of the species and the production of nutrients? Can both morphological traits and nutrient content discriminate the accessions according to their geographic origin? We also discuss the significance of our results for G. gynandra towards breeding for improved nutritional value and leaf yield.

\section{Materials and methods}

\section{Plant material}

A total of 76 diverse accessions of G. gynandra were selected from germplasm collections of the World Vegetable Center, the Laboratory of Genetics, Horticulture and Seed Science in Benin, the University of Ouagadougou in Burkina Faso and the Kenya Resource Center for Indigenous Knowledge. The selection of these accessions considered the variation in plant architecture and geographical origin in each collection. The detailed list of accessions and their provenance is presented in Table 1 . The plants were grown under irrigated conditions with a defined light period (16-h day/8-h night) and temperature $\left(24^{\circ} \mathrm{C}\right.$ day $/ 20^{\circ} \mathrm{C}$ night $)$ in a greenhouse at Wageningen University from December 2016 to April 2017. The seeds were germinated on coco peat, and three seedlings per accession were selected 1 week after sowing and transplanted on rockwool blocks. From each accession, 10-15 leaves were harvested 8 weeks after sowing, immediately frozen in liquid nitrogen, bulked per accession, ground into a fine powder and stored at $-80{ }^{\circ} \mathrm{C}$ until nutrient analysis. A pooled sample of leaves from all accessions was prepared and used as technical replicates for determining analytical variation during the biochemical analyses.

\section{Morphological characterization}

The morphological characterization of the accessions was conducted using a set of 27 descriptors including 15 quantitative and 12 qualitative scores (Supplementary material 1). Quantitative traits assessed included: days to germination, flowering time, plant height, stem diameter, leaflet length, leaflet width, leaf area, petiole length, filament length, gynophore length, androphore length, pedicel length, pod length, pod width and 1000-seed weight. Qualitative traits observed included: plant habit, branching habit, stem colour, stem hairiness, leaf blade lobbing, leaf colour, leaf pubescence, leaf oiliness, leaflet shape, petiole colour, flower colour and leaf margin shape. The flowering time was recorded as the number of days from germination to flowering.

\section{Extraction and analysis of carotenoids, tocopherols and chlorophylls}

Five hundred milligrams fresh weight of ground leaves was freeze-dried overnight and extracted with $4.5 \mathrm{ml}$ of methanol/chloroform $(1: 1, \mathrm{v} / \mathrm{v})$ containing $0.1 \%$ butylated hydroxytoluene (BHT) as antioxidant and $10 \mu \mathrm{M}$ Sudan 1 as internal standard. After vortexing, samples were sonicated for $15 \mathrm{~min}$ and centrifuged at $2500 \mathrm{rpm}$ for $10 \mathrm{~min}$. Then, $2 \mathrm{ml}$ of the supernatant was transferred to a new tube and dried under a gentle nitrogen flow. The dried samples were dissolved in $1 \mathrm{ml}$ of ethanol containing $0.1 \%$ BHT, sonicated for $5 \mathrm{~min}$ and centrifuged at $2000 \mathrm{~g}$ for $5 \mathrm{~min}$. The clear supernatant was transferred to amber vials for high-performance liquid chromatography (HPLC) analysis.

HPLC analysis was performed according to Wahyuni et al. (2011) using a YMC Pack reverse-phase C30 column $(250 \times 4.6 \mathrm{~mm} ; 5 \mu \mathrm{m})$ coupled to a $20 \times 4.6 \mathrm{~mm} \mathrm{C} 30$ guard (YMC Inc. Wilmington, NC, USA), maintained at $35{ }^{\circ} \mathrm{C}$. Chromatography was carried out on a Waters system consisting of a no. 2890 quaternary pump, no. 2996 photodiode array detector (PDA) and no. 2475 fluorescence detector. The mobile phase used was methanol, tert-methyl butyl ether and water/methanol $(1: 4, v / v)$ containing $0.2 \%$ ammonium acetate. Flow rate was $1 \mathrm{ml} / \mathrm{min}$. Data were collected and analysed using the Waters Empower software. Carotenoids were detected by setting the PDA to scan from 220 to $700 \mathrm{~nm}$. Measurements for $\beta$-carotene, $\alpha$-carotene and lutein were taken at $478 \mathrm{~nm}$, violaxanthin at $440 \mathrm{~nm}$, chlorophyll b at $470 \mathrm{~nm}$ and chlorophyll a at $665 \mathrm{~nm}$. Tocopherols were detected by excitation at $296 \mathrm{~nm}$ and emission at $340 \mathrm{~nm}$ (Supplementary material 2). Quantitative determination of compounds was conducted by comparison with dose-response curves constructed from authentic standards. To check the technical variation, including extraction, sample analysis and data processing, quality control samples were prepared from pooled leaf material of several randomly chosen accessions, extracted using the same procedure and injected after every eight accession sample extracts.

\section{Extraction and analysis of ascorbic acid}

The extraction and analysis of ascorbic acid (vitamin C) was made as previously described by Wahyuni et al. (2011). An extraction solution of 5\% metaphosphoric acid 
in purified water containing $1 \mathrm{mM}$ diethylenetriaminepentaacetic acid was prepared. Three hundred milligrams of frozen and grinded material was weighed in cold 2-ml Eppendorf tubes and $1.2 \mathrm{ml}$ of ice-cold extraction solution added. The extracts were vortexed, sonicated for $15 \mathrm{~min}$ and centrifuged at $2500 \mathrm{~g}$ for $20 \mathrm{~min}$. The supernatants were filtered over through $0.2-\mu \mathrm{m}$ polytetrafluoroethylene filters and pipetted into amber vials for HPLC-PDA analysis using the same Waters HPLC system as described above. Separation was made at $30{ }^{\circ} \mathrm{C}$ using a YMC-Pro $\mathrm{C}_{18}$ column (YMC Europe $\mathrm{GmbH} ; 150 \times 3.9 \mathrm{~mm}$ ) with $50 \mathrm{mM} \mathrm{KH}{ }_{2} \mathrm{PO}_{4}$ buffer $(\mathrm{pH} \mathrm{4.4)}$ as eluent at a flow of $0.5 \mathrm{ml} / \mathrm{min}$. Quantification was made based on absorbance at $260 \mathrm{~nm}$, using a calibration curve of an authentic L-ascorbic acid standard from Merck. Retention time of chromatographic peak of ascorbic acid in plant extracts was verified by co-elution with the authentic standard (Supplementary material 2). As performed for the previous analysis, quality control samples from pooled leaf material of all accessions were extracted using the same procedure and injected after every eight accession sample extracts.

\section{Statistical analysis}

The results were presented as means \pm standard deviations from the three regions of origin of the accessions. Multivariate analysis of variance (MANOVA) and univariate analysis of variance (ANOVA) were performed to test variations among regions of origin for all the quantitative variables. The $p$ value $\leq 0.05$ was used to denote significant differences between mean values determined by oneway analysis of variance (ANOVA). The Bonferroni post hoc test was used to denote statistically significant values at $p \leq 0.05$. Factorial analysis of mixed data (FAMD) and a hierarchical cluster analysis (HCPC) from the package "FactoMineR" (Le et al. 2008) were performed on combined quantitative and qualitative data to identify discriminating traits and group the accessions. The correlations between analysed variables were assessed using Pearson's correlation coefficient, and their significance was evaluated by Student's $t$ test. Statistical analyses were performed using R software (R Core Team 2017).

\section{Results and discussion}

\section{Morphological variation in the collection}

We found significant levels of variation for all our morphological traits in our broad collection of G. gynandra that includes 22 accessions from Asia, 34 from East-Southern Africa and 20 from West Africa (Table 1). The variability in quantitative morphological descriptors in the collection is summarized in Table 2. All the quantitative traits showed significant variation among accessions. The coefficient of variation among the traits was greater than or equal to $25 \%$ except for flowering time (14\%), filament length (22\%), androphore length (24\%) and 1000-seed weight $(24 \%)$. The highest coefficient of variation was obtained for leaf area (52\%). Despite the low coefficient of variation observed for flowering time, this trait ranged from 42 days in ODS-15-144 (WA19) to 73 days after germination in TOT8915 (ESA26), providing significant variation for potential changes within a breeding programme. Overall, all accessions in our study flowered later than in previous studies. For different sets of accessions from Eastern and Southern Africa, flowering time varied between 31 and 40 days in the field in Kenya (Omondi et al. 2017) and between 20 and 48 days in the field in Taiwan (Wu et al. 2017). The shorter flowering time in these studies might be explained by the variation in temperature, day length and fertilization schemes used but could also be due to the fact that different sets of accessions were used in these studies.

All the quantitative morphological traits showed significant differences with geographical origin except stem diameter and androphore length (Fig. 1). For example, East-Southern African accessions germinated earlier than West African $(p<0.01)$ and Asian $(p<0.001)$ accessions (Fig. 1a). Early flowering occurred in West African accessions, while late flowering accessions were from East and Southern Africa (Fig. 1b). West African accessions had lower leaf dimensions compared with accessions from the other regions $(p<0.001)$ (Fig. 1d-g). East and Southern African accessions had flowers with longer gynophores $(p<0.001)$ and filaments $(p<0.05)$ compared with accessions from the other regions (Fig. 1h), and similar trends were observed for pod length $(p<0.001)$ and seed weight $(p<0.001)$ (Fig. $1 \mathrm{k}, \mathrm{m})$. Asian accessions had shorter $(p<0.001)$ but wider pods $(p<0.001)$ than African accessions (Fig. 1k,l). Wu et al. (2017) used the same set of quantitative descriptors excluding leaf area and days to germination to characterize a collection of 242 accessions of G. gynandra from East-Southern Africa $(n=174)$ and Asia $(n=44)$. Overall, the authors found that accessions from East and Southern Africa had significantly higher average values than Asian accessions for all quantitative descriptors except leaflet width. In our case, even though East-Southern African accessions had higher average values than Asian accessions for leaf area, flowering time, petiole length and filament length, there was no significant difference between both regions for those traits. The 30 accessions from East and Southern Africa characterized in Kenya (Omondi et al. 2017) had shorter plants $(66.6 \pm 7.2 \mathrm{~cm})$ compared with our results $(109.1 \pm 25.0 \mathrm{~cm})$ and those of $\mathrm{Wu}$ et al. (2017) 
Table 1 List of accessions of Gynandropsis gynandra and their countries and region of origin

\begin{tabular}{|c|c|c|c|c|}
\hline Code & Accessions & Country of origin & Region & Source \\
\hline AS1 & Gyn & Malaysia & Asia & Wageningen University and Research \\
\hline AS2 & TOT1048 & Thailand & Asia & World Vegetable Center \\
\hline AS3 & TOT1480 & Thailand & Asia & World Vegetable Center \\
\hline AS4 & TOT3514 & Laos & Asia & World Vegetable Center \\
\hline AS5 & TOT3527 & Laos & Asia & World Vegetable Center \\
\hline AS6 & TOT3534SC & Laos & Asia & World Vegetable Center \\
\hline AS7 & TOT3536 & Laos & Asia & World Vegetable Center \\
\hline AS8 & TOT4935 & Thailand & Asia & World Vegetable Center \\
\hline AS9 & TOT4937 & Thailand & Asia & World Vegetable Center \\
\hline AS10 & TOT4976 & Thailand & Asia & World Vegetable Center \\
\hline AS11 & TOT5799 & Thailand & Asia & World Vegetable Center \\
\hline AS12 & TOT7196 & Malaysia & Asia & World Vegetable Center \\
\hline AS13 & TOT7197 & Malaysia & Asia & World Vegetable Center \\
\hline AS14 & TOT7198 & Malaysia & Asia & World Vegetable Center \\
\hline AS15 & TOT7199 & Malaysia & Asia & World Vegetable Center \\
\hline AS16 & TOT7200SC & Malaysia & Asia & World Vegetable Center \\
\hline AS17 & TOT7441 & Laos & Asia & World Vegetable Center \\
\hline AS18 & TOT7449 & Laos & Asia & World Vegetable Center \\
\hline AS19 & TOT7462 & Laos & Asia & World Vegetable Center \\
\hline AS20 & TOT7486 & Laos & Asia & World Vegetable Center \\
\hline AS21 & TOT7505 & Laos & Asia & World Vegetable Center \\
\hline AS22 & TOT8996 & Taiwan & Asia & World Vegetable Center \\
\hline ESA1 & BAR 1807B & Kenya & East and Southern Africa & National Museums of Kenya \\
\hline ESA2 & BGM 2107 & Kenya & East and Southern Africa & National Museums of Kenya \\
\hline ESA3 & ELG 19/07A & Kenya & East and Southern Africa & National Museums of Kenya \\
\hline ESA4 & GA-01 & Kenya & East and Southern Africa & National Museums of Kenya \\
\hline ESA5 & $\mathrm{HBY} / 2307 \mathrm{~b}$ & Kenya & East and Southern Africa & National Museums of Kenya \\
\hline ESA6 & KF-14 & Kenya & East and Southern Africa & National Museums of Kenya \\
\hline ESA7 & $\mathrm{KRC} / 2507 \mathrm{a}$ & Kenya & East and Southern Africa & National Museums of Kenya \\
\hline ESA8 & KSI 2407A & Kenya & East and Southern Africa & National Museums of Kenya \\
\hline ESA9 & KTI/0602 & Kenya & East and Southern Africa & National Museums of Kenya \\
\hline ESA10 & KW-01 & Kenya & East and Southern Africa & National Museums of Kenya \\
\hline ESA11 & NRK-2007A & Kenya & East and Southern Africa & National Museums of Kenya \\
\hline ESA12 & RW-SF-10 & Rwanda & East and Southern Africa & World Vegetable Center \\
\hline ESA13 & TNZ 2107B & Kenya & East and Southern Africa & National Museums of Kenya \\
\hline ESA14 & ТОT6420 & Tanzania & East and Southern Africa & World Vegetable Center \\
\hline ESA15 & TOT6421 & Tanzania & East and Southern Africa & World Vegetable Center \\
\hline ESA16 & TOT6439 & Zambia & East and Southern Africa & World Vegetable Center \\
\hline ESA17 & TOT6440 & South Africa & East and Southern Africa & World Vegetable Center \\
\hline ESA18 & TOT6441 & South Africa & East and Southern Africa & World Vegetable Center \\
\hline ESA19 & TOT6442 & South Africa & East and Southern Africa & World Vegetable Center \\
\hline ESA20 & ТОТ8887 & Uganda & East and Southern Africa & World Vegetable Center \\
\hline ESA21 & ТОТ8888 & Uganda & East and Southern Africa & World Vegetable Center \\
\hline ESA22 & ТОТ8889 & Uganda & East and Southern Africa & World Vegetable Center \\
\hline ESA23 & TOT8890 & Uganda & East and Southern Africa & World Vegetable Center \\
\hline ESA24 & ТОТ8891 & Uganda & East and Southern Africa & World Vegetable Center \\
\hline ESA25 & TOT8892 & Uganda & East and Southern Africa & World Vegetable Center \\
\hline ESA26 & TOT8915 & Malawi & East and Southern Africa & World Vegetable Center \\
\hline ESA27 & TOT8916 & Malawi & East and Southern Africa & World Vegetable Center \\
\hline ESA28 & TOT8917 & Malawi & East and Southern Africa & World Vegetable Center \\
\hline
\end{tabular}


Table 1 (continued)

\begin{tabular}{|c|c|c|c|c|}
\hline Code & Accessions & Country of origin & Region & Source \\
\hline ESA29 & TOT8918 & Malawi & East and Southern Africa & World Vegetable Center \\
\hline ESA30 & TOT8925G & Kenya & East and Southern Africa & World Vegetable Center \\
\hline ESA31 & TOT8931 & South Africa & East and Southern Africa & World Vegetable Center \\
\hline ESA32 & TOT8933 & Zambia & East and Southern Africa & World Vegetable Center \\
\hline ESA33 & TOT8998 & Uganda & East and Southern Africa & World Vegetable Center \\
\hline ESA34 & TT-00 & Kenya & East and Southern Africa & National Museums of Kenya \\
\hline WA1 & INC-04-015 & Burkina Faso & West Africa & University of Ouagadougou \\
\hline WA2 & INC-06-015 & Burkina Faso & West Africa & University of Ouagadougou \\
\hline WA3 & INC-08-015 & Burkina Faso & West Africa & University of Ouagadougou \\
\hline WA4 & ODS-14-008 & Benin & West Africa & University of Abomey-Calavi \\
\hline WA5 & ODS-15-002 & Benin & West Africa & University of Abomey-Calavi \\
\hline WA6 & ODS-15-013 & Benin & West Africa & University of Abomey-Calavi \\
\hline WA7 & ODS-15-020 & Benin & West Africa & University of Abomey-Calavi \\
\hline WA8 & ODS-15-033 & Benin & West Africa & University of Abomey-Calavi \\
\hline WA9 & ODS-15-038 & Benin & West Africa & University of Abomey-Calavi \\
\hline WA10 & ODS-15-044 & Benin & West Africa & University of Abomey-Calavi \\
\hline WA11 & ODS-15-045 & Togo & West Africa & University of Abomey-Calavi \\
\hline WA12 & ODS-15-065 & Togo & West Africa & University of Abomey-Calavi \\
\hline WA13 & ODS-15-068 & Togo & West Africa & University of Abomey-Calavi \\
\hline WA14 & ODS-15-084 & Togo & West Africa & University of Abomey-Calavi \\
\hline WA15 & ODS-15-094 & Togo & West Africa & University of Abomey-Calavi \\
\hline WA16 & ODS-15-100 & Togo & West Africa & University of Abomey-Calavi \\
\hline WA17 & ODS-15-104 & Ghana & West Africa & University of Abomey-Calavi \\
\hline WA18 & ODS-15-111 & Ghana & West Africa & University of Abomey-Calavi \\
\hline WA19 & ODS-15-114 & Ghana & West Africa & University of Abomey-Calavi \\
\hline WA20 & ODS-15-121 & Ghana & West Africa & University of Abomey-Calavi \\
\hline
\end{tabular}

$(115 \pm 27 \mathrm{~cm})$. Similar to the case of flowering time, the differences in plant height could also be explained by a difference in environmental conditions, cultivation practices and the germplasm collections used. The variation in 1000 -seed weight was comparable between all the studies and ranged from 1.44 to $1.71 \mathrm{~g}$ in Kenya (Omondi et al. 2017), 1.0 and $2.2 \mathrm{~g}$ in Taiwan (Wu et al. 2017) and $0.7-1.8 \mathrm{~g}$ in our study.

The collection exhibited a wide variation in qualitative morphological descriptors. The geographical origin of the accessions was significantly associated with plant habit, leaflet shape, leaf colour and stem hairiness. Accessions with a spreading growth habit originated from West Africa (35\%) and Asia (4.5\%), while all accessions from East-Southern Africa had an upright (17.6\%) or intermediate (82.4\%) habit. Most Asian accessions (77.3\%) had deltoid leaflets, while African accessions had either elliptic or lanceolate leaflets. Only East African accessions had dark green leaves (44.1\%), while accessions from the other regions had green or light green leaves. None of the accessions from Asia had a glabrous stem and all exhibited various levels of stem hairiness from moderately hairy to densely hairy. In contrast, West African accessions had a high percentage of glabrous stems $(65 \%)$ and none of them had a densely hairy stem.

\section{Variation in carotenoids, tocopherols and ascorbic acid}

The carotenoids detected in the leaves included lutein, violaxanthin, $\alpha$-carotene and $\beta$-carotene. Chlorophylls a and $\mathrm{b}$ were also quantified and provided a reliable measure of the "greenness" of the leaves. The total carotenoids concentration varied from $36.9 \mu \mathrm{g} / \mathrm{g}$ FW in ODS-15-094 (WA15) to $95.8 \mu \mathrm{g} / \mathrm{g} \mathrm{FW}$ in BAR1807B (ESA1). The predominant carotenoids were lutein $(21-56 \mu \mathrm{g} / \mathrm{g}$ FW with a coefficient of variation of $19.7 \%$ ) and $\beta$-carotene (11.8-34.9 $\mu \mathrm{g} / \mathrm{g} \mathrm{FW}$ with a coefficient of variation of $19.5 \%$ ), accounting for an average of $56 \%$ and $35 \%$ of the total carotenoids, respectively. Overall, East-Southern African accessions had higher levels of carotenoids and chlorophylls compared with West African and Asian accessions except for violaxanthin for which no significant differences were observed among regions 
(Fig. 2a-f). Previous studies on the species reported higher levels of $\beta$-carotene: $41.2 \mu \mathrm{g} / \mathrm{g} \mathrm{FW}$ (Schönfeldt and Pretorius 2011), $59.4 \mu \mathrm{g} / \mathrm{g}$ FW (van Jaarsveld et al. 2014) and 57.1 and $64.7 \mu \mathrm{g} / \mathrm{g} \mathrm{DW}$ (Neugart et al. 2017), and analyses were performed on a single genotype. Such differences in absolute levels between studies may be explained by the differences in the growing conditions, developmental stages of leaves and the genotypes analysed.

The main forms of tocopherols determined in all accessions were $\alpha$ - and $\gamma$-tocopherols (vitamin E). $\alpha$ - and $\gamma$-tocopherols have also been identified in significant levels in seven cultivars of Brassica oleracea (Guzman et al. 2012). The levels of $\alpha$-tocopherol varied from 151.0 to $264.5 \mu \mathrm{g} / \mathrm{g}$ and the levels of $\gamma$-tocopherol from 50.9 to $93.6 \mu \mathrm{g} / \mathrm{g}$. Of the many different forms of vitamin $\mathrm{E}, \alpha$-tocopherol is the most abundant form in nature and is the form preferably retained in human body (Jiang 2014). The concentration of $\alpha$-tocopherol, the predominant form in $G$. gynandra leaves, ranged from $1.8 \mu \mathrm{g} / \mathrm{g} \mathrm{FW}$ in TOT8889 (ESA22) to $37.2 \mu \mathrm{g} / \mathrm{g}$ FW in ODS-15-013 (WA6) with a coefficient of variation of $56.6 \%$, while the concentration in $\gamma$-tocopherol ranged from $0.02 \mu \mathrm{g} / \mathrm{g}$ FW in TOT6421 (ESA15) and TOT8892 (ESA25) to $0.4 \mu \mathrm{g} / \mathrm{g}$ FW in TOT7198 (AS14) with a coefficient of variation of $73.5 \%$. West African accessions had higher average levels of $\alpha$-tocopherol compared with accessions from the other regions (Fig. 2g). In contrast, Asian accessions had the highest levels of $\gamma$-tocopherol (Fig. $2 \mathrm{~g}$ ). To our knowledge, this is the first report of vitamin E quantification in $G$. gynandra. Levels of $\alpha$-tocopherol comparable with our results were reported in other vegetables including lettuce (1.5-3.6 $\mu \mathrm{g} / \mathrm{g} \mathrm{FW),} \mathrm{watercress} \mathrm{(7.2} \mu \mathrm{g} / \mathrm{g} \mathrm{FW)} \mathrm{(Cruz}$ and Casal 2013) and broccoli (27.2 $\mu \mathrm{g} / \mathrm{g}$ FW) (GranadoLorencio et al. 2007).
A ninefold variation in ascorbic acid (vitamin C) was observed in the collection from $173.7 \mu \mathrm{g} / \mathrm{g}$ FW in TOT7197 (AS13) to $1556.8 \mu \mathrm{g} / \mathrm{g}$ FW in TOT4935 (AS8) with an average of $849.1 \pm 272.8 \mu \mathrm{g} / \mathrm{g} \mathrm{FW}$ and a coefficient of variation of $31.9 \%$. Jiménez-Aguilar and Grusak (2015) also indicated high levels of ascorbic acid, ranging from 1060 to $1400 \mu \mathrm{g} / \mathrm{g}$ FW in G. gynandra accessions collected in Zambia. No geographic pattern of variation was associated with ascorbic acid levels in the collection (Fig. 2i).

The large variability in the levels of the selected nutrients in the collection provides an important opportunity for breeding the species for higher nutrient contents. However, correlations between nutrients and between nutrients and morphological traits are critical for the design of appropriate breeding strategies.

\section{Relationships between accessions and trait correlations}

Accessions were classified in three main clusters based on the factorial analysis of mixed data including the 27 morphological descriptors and the levels of nutrients (Fig. 3a). The first cluster included only accessions from West Africa (100\%) (Fig. 3a). Cluster 2 predominantly consisted of accessions from Asia (92\%) with few accessions from East-Southern Africa (8\%). Accessions in cluster 3 were mainly from East-Southern Africa (97\%) with some accessions from West Africa (3\%) (Fig. 3c). Overall, clusters 1 and 2 made of accessions from West Africa and Asia, respectively, were closer than cluster 3 which encompasses mainly accessions from East Africa. Similar patterns of relationships between $G$. gynandra accessions from the three regions were revealed by Reeves et al. (2018) based on internal transcribed spacer sequences. Wu et al. (2017)
Table 2 Descriptive statistics for the morphological quantitative descriptors in the collection of Gynandropsis gynandra

\begin{tabular}{lrccc}
\hline Morphological characters & Mean & $\begin{array}{l}\text { Standard devia- } \\
\text { tion }\end{array}$ & $\begin{array}{l}\text { Coefficient of varia- } \\
\text { tion (\%) }\end{array}$ & Range \\
\hline Days to germination & 6.30 & 1.62 & 25.65 & $4-14$ \\
Flowering time (days) & 53.95 & 7.48 & 13.86 & $42-73$ \\
Leaf area $\left(\mathrm{cm}^{2}\right)$ & 32.74 & 17.24 & 52.64 & $3.72-125.16$ \\
Plant height (cm) & 80.61 & 31.43 & 38.98 & $19.00-168.00$ \\
Stem diameter (mm) & 9.44 & 2.04 & 21.62 & $2.81-15.43$ \\
Leaflet length (cm) & 5.72 & 1.50 & 26.19 & $2.15-12.09$ \\
Leaflet width (cm) & 2.55 & 0.69 & 27.20 & $0.70-4.63$ \\
Petiole length (cm) & 8.42 & 2.99 & 35.49 & $1.43-26.00$ \\
Filament length (mm) & 15.45 & 3.32 & 21.51 & $7.18-29.43$ \\
Gynophore length (mm) & 12.82 & 3.96 & 30.92 & $4.95-24.31$ \\
Androphore length (mm) & 14.46 & 3.50 & 24.21 & $5.96-31.47$ \\
Pedicel length (mm) & 15.39 & 3.69 & 23.98 & $7.97-26.83$ \\
Pod length (mm) & 74.02 & 20.49 & 27.69 & $39.54-142.59$ \\
Pod width (mm) & 7.63 & 2.60 & 34.06 & $1.85-17.15$ \\
1000-seed weight (mg) & 1.17 & 0.28 & 23.54 & $0.54-1.99$ \\
\hline
\end{tabular}


(a) Days to germination

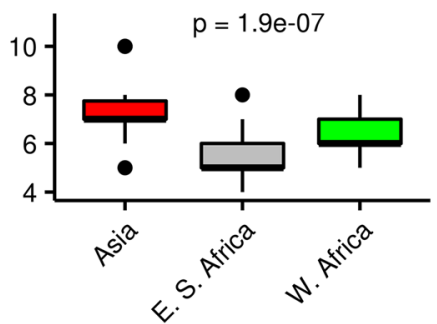

(d) Leaf area $\left(\mathrm{cm}^{2}\right)$

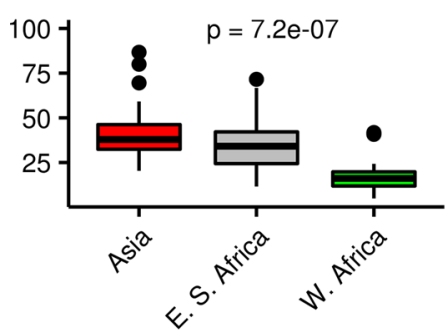

(g) Petiole length (cm)

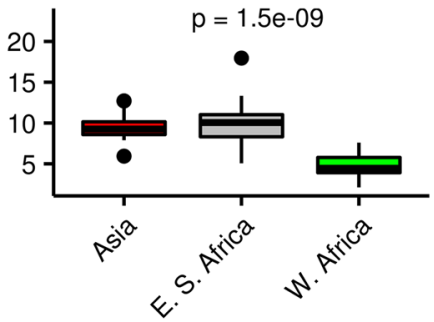

(j) Pedicel length (mm)

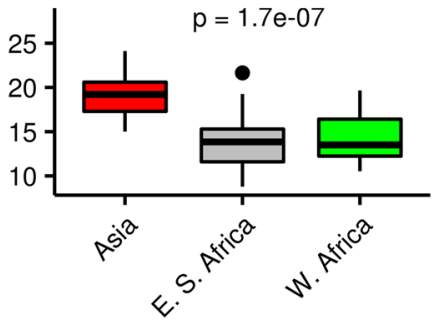

(m) 1000 seeds weight (g)

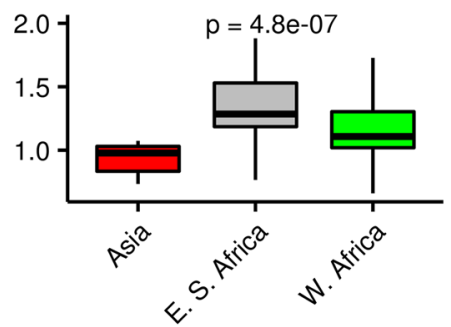

Region (b) Flowering time (days)

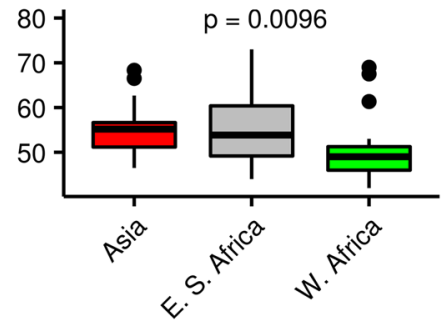

(e) Leaflet length $(\mathrm{cm})$

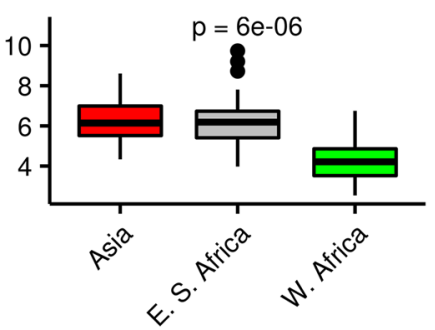

(h) Filament length $(\mathrm{mm})$

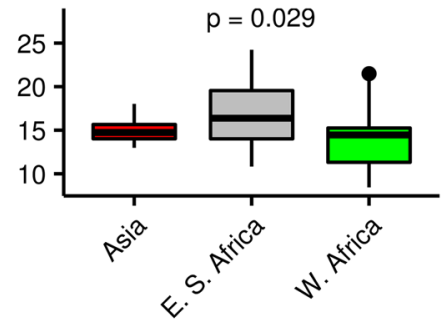

(k) Pod length (mm)

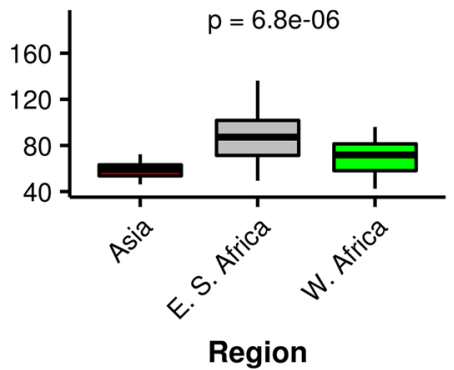

(c) Plant height (cm)

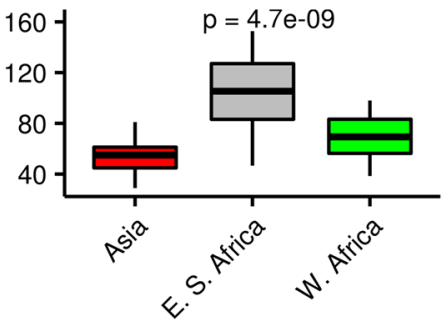

(f) Leaflet width $(\mathrm{cm})$

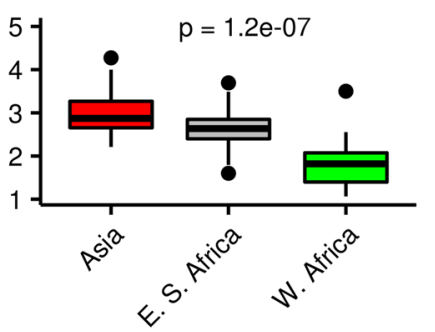

(i) Gynophore length ( $\mathrm{mm}$ )

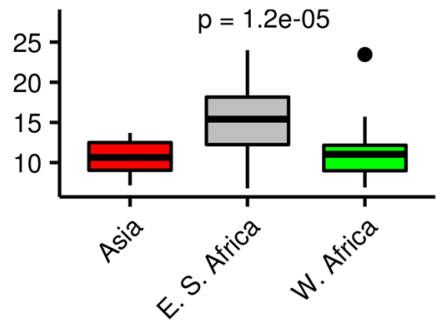

(I) Pod width (mm)

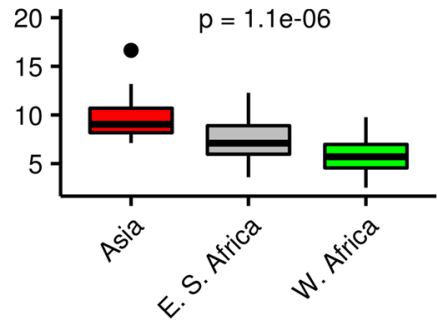

Region

Fig. 1 Box plots showing natural variation in morphological descriptors among Asian $(n=22)$, East-Southern African $(n=34)$ and West African accessions $(n=20)$ of Gynandropsis gynandra 
previously compared morphological features between African and Asian accessions of G. gynandra and showed differentiation based on geographic origin. However, their study included only accessions from East and Southern Africa and none from West Africa. All the qualitative traits except leaf blade lobbing, leaf pubescence and leaf oiliness contributed (a) $\alpha$-carotene

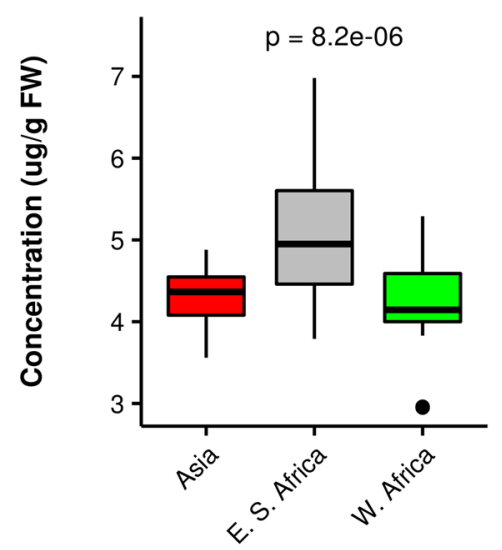

(d) Violaxanthin

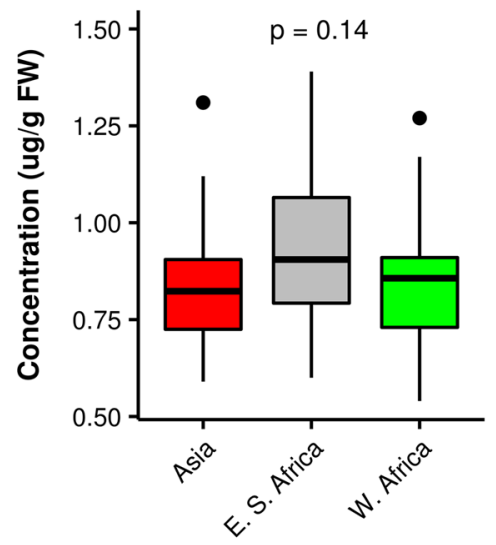

(g) $\alpha$-tocopherol

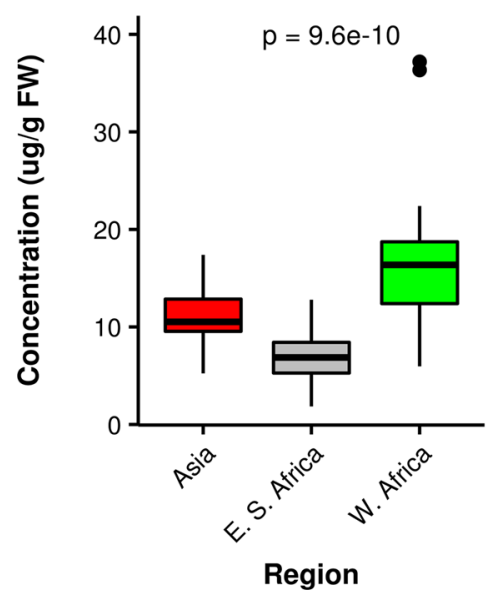

(b) $\beta$-carotene

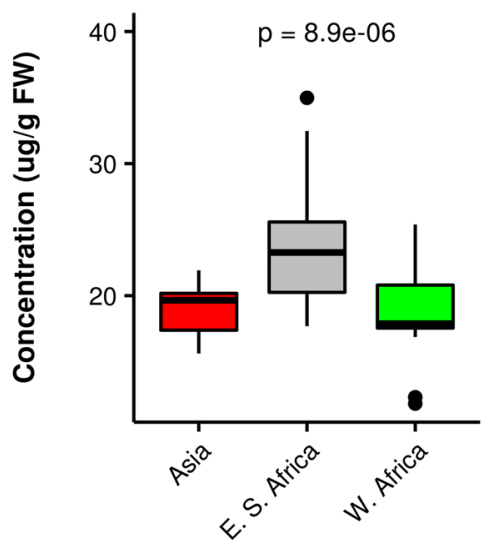

(e) Chlorophyll a

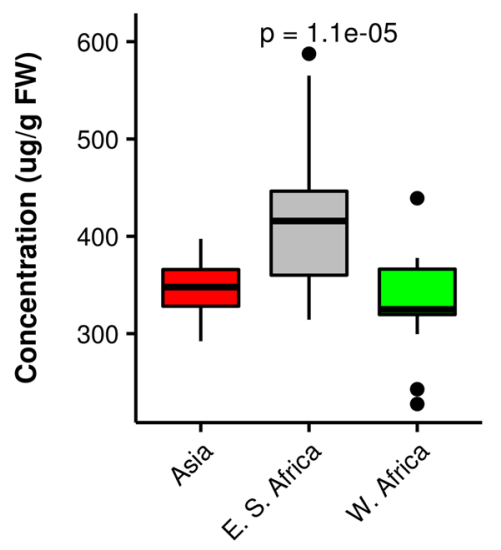

(h) $\gamma$-tocopherol

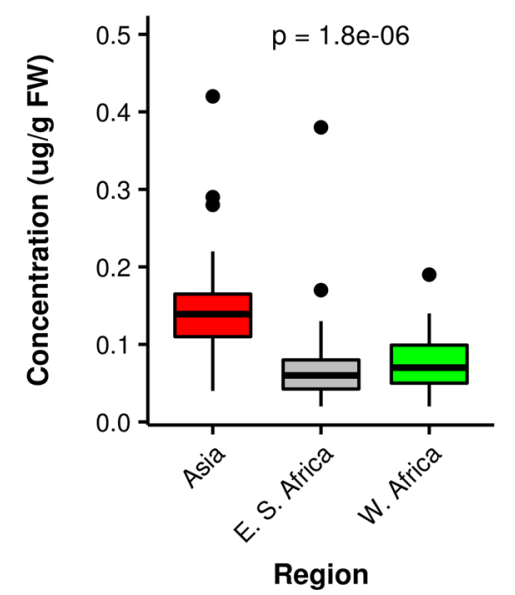

(c) Lutein

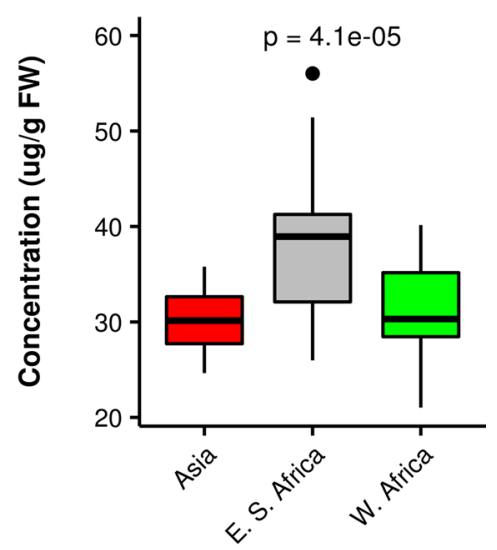

(f) Chlorophyll b

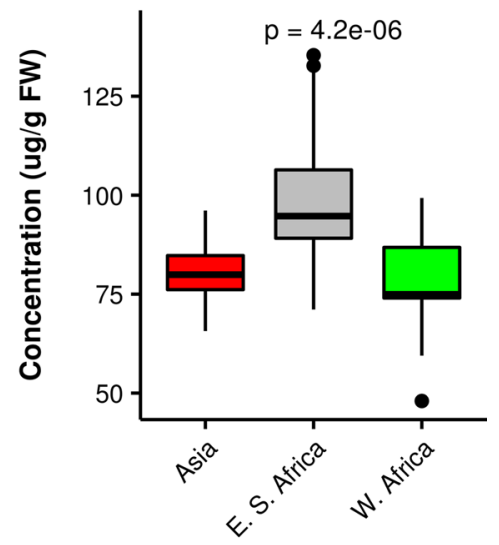

(i) Ascorbic acid

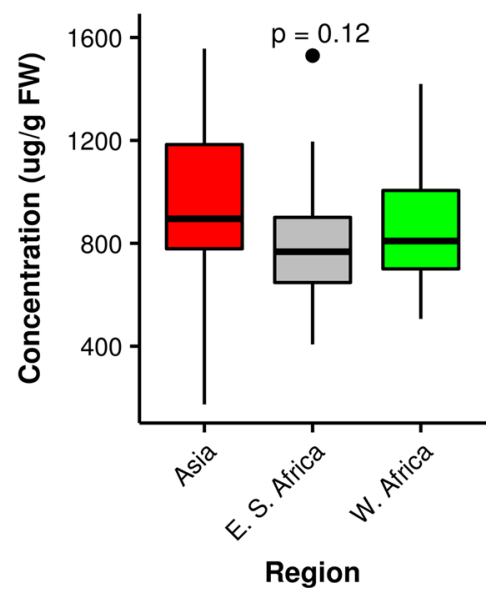

Fig. 2 Box plots showing natural variation in levels of carotenoids, chlorophylls, tocopherols and ascorbic acid among Asian ( $n=22)$, EastSouthern African $(n=34)$ and West African $(n=20)$ accessions of Gynandropsis gynandra 
to the classification of the accessions (Table 3). Morphological quantitative traits including plant height, leaflet length, leaflet width, filament length and pedicel length as well as levels of $\beta$-carotene, lutein, chlorophyll a and $\alpha$-tocopherol were the most important variables which contributed to the differentiation of the accessions (Fig. 3b). Cluster 1 was characterized by short plants with small leaves, high levels in $\alpha$-tocopherol and relatively low levels in carotenoids. (a)

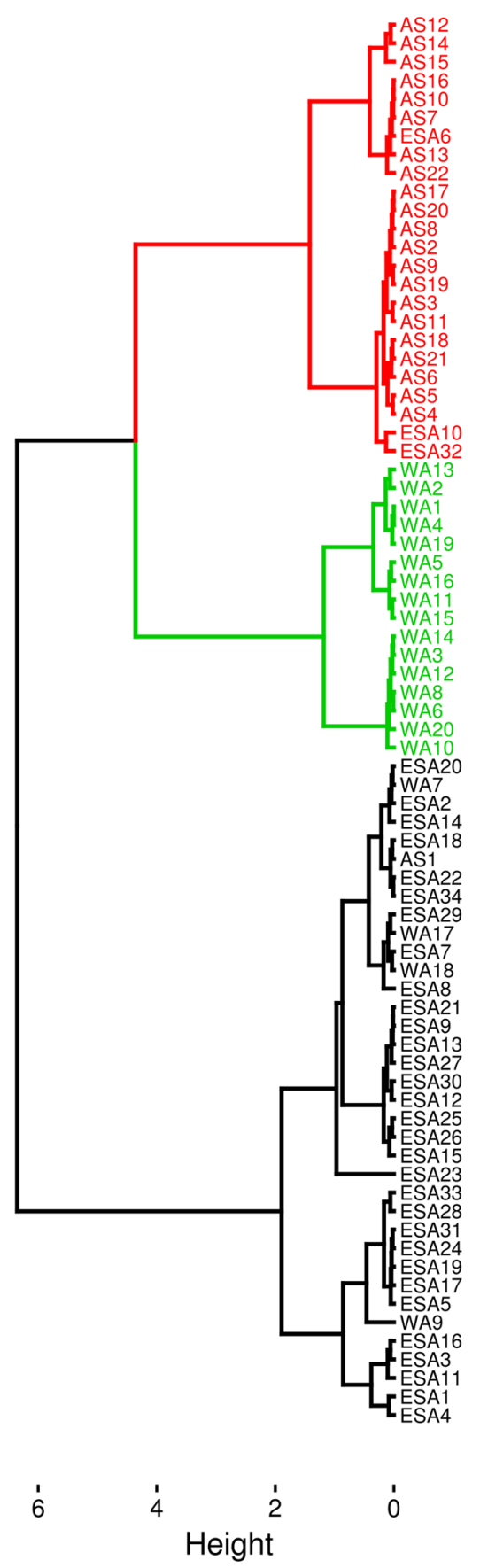

(b)

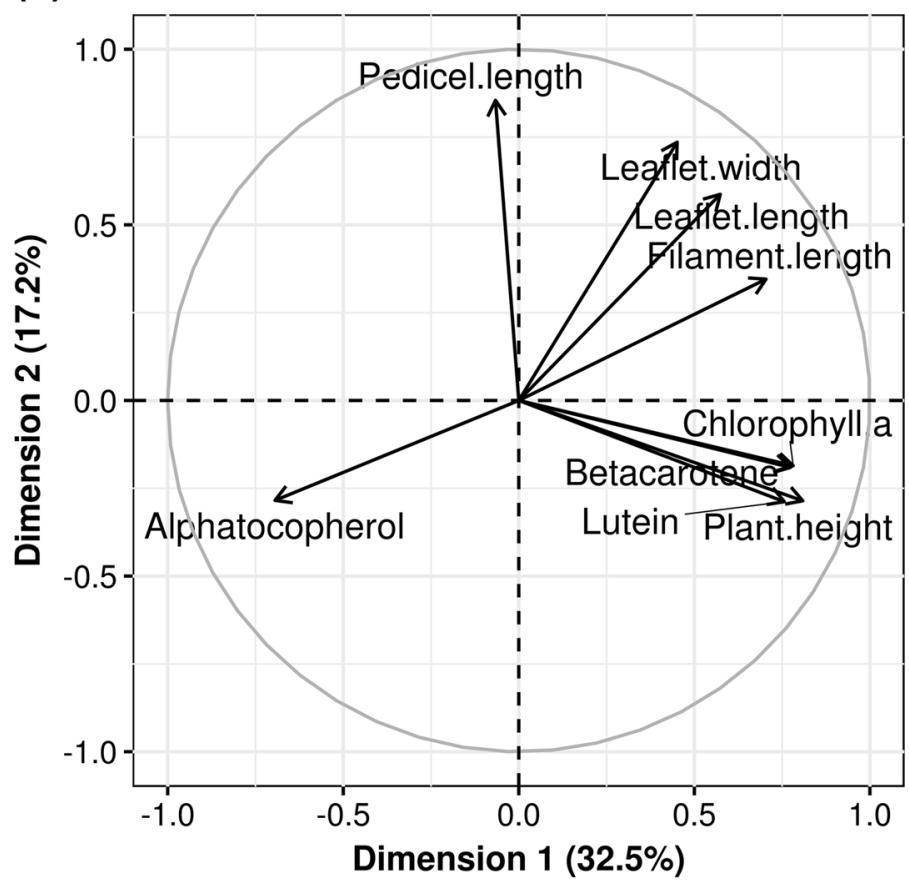

(c)

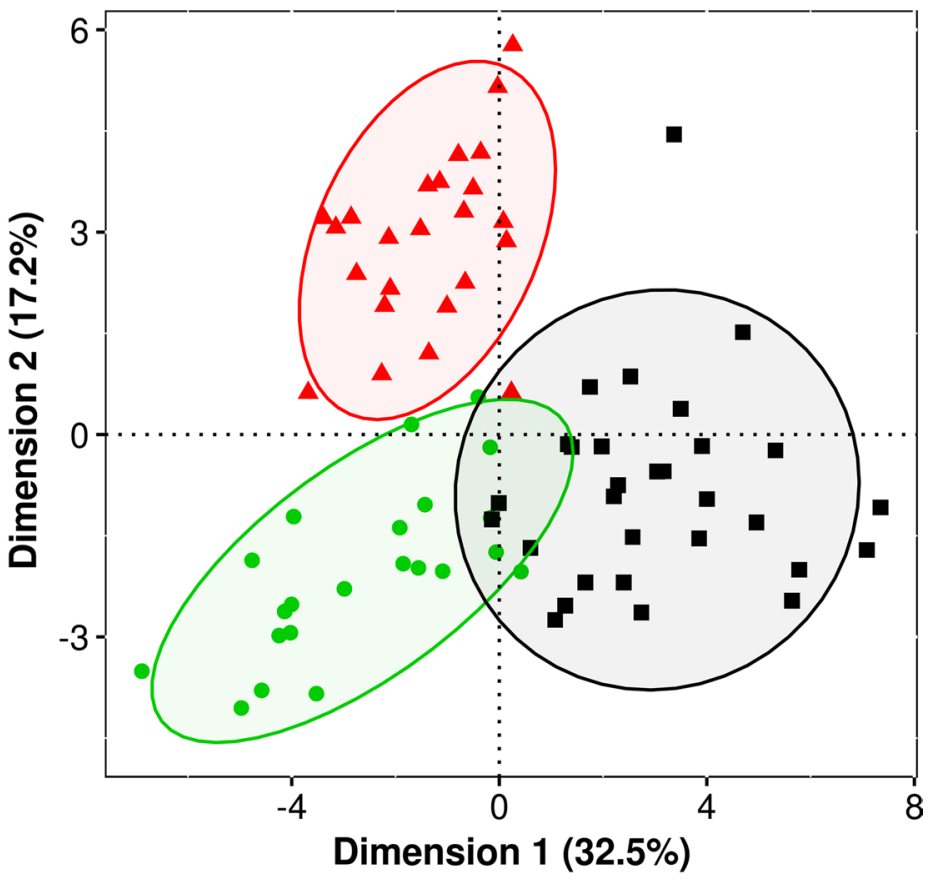

Fig. 3 Clustering of the 76 accessions of Gynandropsis gynandra based on morphological descriptors and levels of nutrients. a Dendrogram based on hierarchical clustering of both quantitative and qualitative data; $\mathbf{b}$ correlation circle based on principal component analysis; only variables significantly represented on the principal components $(\cos 2>0.5)$ are displayed. c Score plot of accessions based on hierarchical clustering on principal components 
Cluster 2 included accessions with short plants, broad leaves and long pedicels and relatively low levels of carotenoids and high levels of tocopherols, while Cluster 3 was made of accessions with tall plants and high levels of carotenoids and chlorophylls (Fig. 3c; Table 4).

The Pearson correlation matrix indicated significant positive correlations between lutein, $\alpha$-carotene, $\beta$-carotene, chlorophyll a and chlorophyll b (Fig. 4). Significantly positive correlations were observed between levels of carotenoids and chlorophylls and plant height, leaflet length, petiole length, filament length, gynophore length, pod length and 1000-seed weight, suggesting that taller and bigger accessions with dark green leaves are likely to have higher carotenoids content. In contrast, strong negative correlations were observed between $\alpha$-tocopherol and plant height, stem diameter, leaflet length, leaflet width, petiole length, leaf area, filament length, gynophore length and androphore length, carotenoids and chlorophylls. The correlations between morphological traits and carotenoid, tocopherol and chlorophyll content might be explained by the fact that the morphology of the different accessions evolved as a response to various environmental factors as was also the case for the production of photosynthesis-related compounds such as carotenoids, tocopherols and chlorophylls. No significant correlation was found between ascorbic acid (vitamin C) and other nutrients. Carotenoids (pro-vitamin A), ascorbate (vitamin C), tocopherols (vitamin E) all play a major role in the elimination of reactive oxygen species in chloroplasts (Asensi-Fabado and Munné-Bosch 2010). However, while the carotenoid, tocopherol and chlorophyll biosynthetic pathways share geranylgeranyl diphosphate as a precursor, there is no direct relationship between these pathways and
Table 3 Description of clusters of accessions of Gynandropsis gynandra according to regions and qualitative descriptors

\begin{tabular}{|c|c|c|c|c|}
\hline Descriptors & Modalities & Cluster $1(\%)$ & Cluster $2(\%)$ & Cluster $3(\%)$ \\
\hline \multirow[t]{3}{*}{ Region } & East Africa & 0 & 8 & 97 \\
\hline & West Africa & 100 & 0 & 3 \\
\hline & South-East Asia & 0 & 92 & 0 \\
\hline \multirow[t]{3}{*}{ Growth habit } & Upright & 50 & 42 & 80 \\
\hline & Intermediate & 23 & 54 & 17 \\
\hline & Spreading & 27 & 4 & 3 \\
\hline \multirow[t]{3}{*}{ Branching habit } & Sparse & 73 & 12 & 33 \\
\hline & Intermediate & 23 & 88 & 60 \\
\hline & Abundant & 4 & 0 & 7 \\
\hline \multirow{6}{*}{$\begin{array}{l}\text { Stem colour }(0=\text { entirely } \\
\text { green to } 5=\text { entirely purple })\end{array}$} & 0 & 45 & 12 & 20 \\
\hline & 1 & 9 & 4 & 7 \\
\hline & 2 & 23 & 21 & 13 \\
\hline & 3 & 13 & 42 & 7 \\
\hline & 4 & 5 & 17 & 20 \\
\hline & 5 & 5 & 4 & 33 \\
\hline \multirow[t]{4}{*}{ Stem hairiness } & Glabrous & 64 & 0 & 4 \\
\hline & Scantly hairy & 27 & 29 & 53 \\
\hline & Moderately hairy & 9 & 33 & 33 \\
\hline & Very hairy or woolly & 0 & 38 & 10 \\
\hline \multirow[t]{3}{*}{ Leaf colour } & Light green & 10 & 4 & 0 \\
\hline & Green & 90 & 96 & 50 \\
\hline & Dark green & 0 & 0 & 50 \\
\hline \multirow[t]{3}{*}{ Terminal leaflet shape } & Deltoid & 4 & 76 & 0 \\
\hline & Elliptic & 41 & 20 & 83 \\
\hline & Lanceolate & 55 & 4 & 17 \\
\hline \multirow[t]{3}{*}{ Leaf margin } & Entire & 68 & 42 & 80 \\
\hline & Ondulate & 23 & 54 & 20 \\
\hline & Serrate & 9 & 4 & 0 \\
\hline \multirow[t]{4}{*}{ Flower colour } & White & 95 & 75 & 80 \\
\hline & Pink & 5 & 4 & 4 \\
\hline & Purple & 0 & 4 & 16 \\
\hline & Yellow & 0 & 17 & 0 \\
\hline
\end{tabular}


the biosynthesis of ascorbate. Phenotyping of segregating populations from crosses between contrasting parents will be required to further investigate the observed correlations between morphological traits and vitamin content. The summary of the differences between the three clusters of accessions is presented in Fig. 5.

Both carotenoids and tocopherols are synthesized in whole or in part from the plastidic isoprenoid biosynthetic pathway (DellaPenna and Pogson 2006). As carotenoids, tocopherols and chlorophylls are photosynthetic pigments, we expected positive correlations among those compounds. However, Reeves et al. (2018) observed variation in photosynthesis-related traits in $G$. gynandra which corroborate the differences that we observed in terms of carotenoids and tocopherols content. The authors found that compared with East African accessions, Asian and West African accessions had higher water use efficiency, lower density of stomata and veins and larger bundle sheath areas and cell sizes. Moreover, the Asian and West African accessions had increased expression of genes encoding $\mathrm{C}_{4}$ enzymes. Such genetic variation could be induced by geographic or environmental isolation of different populations adapted to local conditions and with limited gene flow among them (Kleessen et al.
2012; Prunier et al. 2017). Several studies documented the geographical patterns of intraspecific differentiation in plant morphology (Pucher et al. 2015; Upadhyaya et al. 2017) and phytochemical profiles (Bellomo and Fallico 2007; da Silva et al. 2017; Masetti et al. 2017; Shepherd et al. 2017). We hypothesize that the observed trade-off between carotenoids and tocopherols associated with geographical origin could be explained by differential expression of some genes involved in carotenoid, chlorophyll and tocopherol synthesis. Depending on whether important genes or transcription factors are upregulated or down regulated in the accessions, the synthesis of rate-limiting precursors on carotenoids, chlorophylls and tocopherols biosynthesis might be affected. For example, phytol released during chlorophyll degradation is essential for tocopherol biosynthesis in plants (vom Dorp et al. 2015). Wunnakup et al. (2018) observed that the transient expression of the homogentisate phytyltransferase (HTP) gene from Clitoria ternatea L. in tomato leaves led to an increase in $\alpha$-tocopherol biosynthesis and caused the degradation of chlorophylls. These convergent results suggest that chlorophyll/tocopherol ratio in plants may vary depending on the levels of expression of HTP. Further studies are required in Gynandropsis gynandra
Table 4 Average value (mean $\pm \mathrm{SD}$ ) of quantitative morphological descriptors and nutrient content in the clusters of Gynandropsis gynandra and the entire collection

\begin{tabular}{|c|c|c|c|c|c|}
\hline Descriptors & Cluster 1 & Cluster 2 & Cluster 3 & Entire collection & $p$ value \\
\hline \multicolumn{6}{|l|}{ Morphological descriptors } \\
\hline Days to germination & $6.5 \pm 0.9$ & $7.0 \pm 1.5$ & $5.6 \pm 1.9$ & $6.3 \pm 1.6$ & 0.002 \\
\hline Days to flowering & $50.4 \pm 7.1$ & $55.4 \pm 6.1$ & $55.4 \pm 8.1$ & $53.9 \pm 7.5$ & 0.029 \\
\hline Leaf area $\left(\mathrm{cm}^{2}\right)$ & $16.5 \pm 7.7$ & $42.3 \pm 17.1$ & $37.0 \pm 14.1$ & $32.7 \pm 17.2$ & $<0.0001$ \\
\hline Plant height $(\mathrm{cm})$ & $71.3 \pm 20.5$ & $53.6 \pm 11.9$ & $109.1 \pm 25.0$ & $80.6 \pm 31.4$ & $<0.0001$ \\
\hline Stem diameter (mm) & $8.7 \pm 2.8$ & $9.5 \pm 1.3$ & $9.9 \pm 1.8$ & $9.4 \pm 2.0$ & 0.121 \\
\hline Leaflet length $(\mathrm{cm})$ & $4.2 \pm 1.0$ & $6.2 \pm 1.1$ & $6.4 \pm 1.2$ & $5.7 \pm 1.5$ & $<0.0001$ \\
\hline Leaflet width (cm) & $1.8 \pm 0.5$ & $3.0 \pm 0.5$ & $2.7 \pm 0.5$ & $2.6 \pm 0.7$ & $<0.0001$ \\
\hline Petiole length $(\mathrm{cm})$ & $4.9 \pm 1.7$ & $9.4 \pm 1.6$ & $10.2 \pm 2.3$ & $8.4 \pm 3.0$ & $<0.0001$ \\
\hline Filament length $(\mathrm{mm})$ & $13.5 \pm 2.9$ & $14.8 \pm 1.4$ & $17.4 \pm 3.7$ & $15.4 \pm 3.3$ & $<0.0001$ \\
\hline Gynophore length (mm) & $10.7 \pm 2.2$ & $10.6 \pm 2.1$ & $16.2 \pm 3.8$ & $12.8 \pm 4.0$ & $<0.0001$ \\
\hline Androphore length (mm) & $14.0 \pm 3.2$ & $13.9 \pm 2.2$ & $15.2 \pm 4.4$ & $14.5 \pm 3.5$ & 0.336 \\
\hline Pedicel length (mm) & $13.8 \pm 2.4$ & $18.9 \pm 2.6$ & $13.7 \pm 3.2$ & $15.4 \pm 3.7$ & $<0.0001$ \\
\hline Pod length (mm) & $72.5 \pm 16.7$ & $59.1 \pm 8.1$ & $87.3 \pm 21.5$ & $74.0 \pm 20.5$ & $<0.0001$ \\
\hline Pod width (mm) & $6.0 \pm 2.1$ & $9.3 \pm 2.6$ & $7.5 \pm 2.1$ & $7.6 \pm 2.6$ & $<0.0001$ \\
\hline 1000-seed weight (mg) & $1.1 \pm 0.2$ & $0.9 \pm 0.1$ & $1.4 \pm 0.2$ & $1.2 \pm 0.3$ & $<0.0001$ \\
\hline \multicolumn{6}{|l|}{ Nutrients } \\
\hline Lutein & $31.1 \pm 4.8$ & $30.1 \pm 3.2$ & $39.0 \pm 6.9$ & $33.9 \pm 6.7$ & $<0.0001$ \\
\hline$\alpha$-Carotene & $4.2 \pm 0.5$ & $4.3 \pm 0.3$ & $5.2 \pm 0.8$ & $4.6 \pm 0.8$ & $<0.0001$ \\
\hline$\beta$-Carotene & $18.8 \pm 3.1$ & $19.1 \pm 1.8$ & $24.0 \pm 4.2$ & $20.9 \pm 4.1$ & $<0.0001$ \\
\hline Violaxanthin & $0.8 \pm 0.2$ & $0.8 \pm 0.1$ & $0.9 \pm 0.2$ & $0.9 \pm 0.2$ & 0.032 \\
\hline Chlorophyll a & $338.0 \pm 47.5$ & $347.0 \pm 27.3$ & $421.8 \pm 66.8$ & $373.9 \pm 64.1$ & $<0.0001$ \\
\hline Chlorophyll b & $78.2 \pm 11.0$ & $79.9 \pm 7.2$ & $100.5 \pm 17.8$ & $87.6 \pm 16.8$ & $<0.0001$ \\
\hline$\alpha$-Tocopherol & $16.3 \pm 8.1$ & $10.9 \pm 2.9$ & $6.9 \pm 2.5$ & $10.9 \pm 6.2$ & $<0.0001$ \\
\hline$\gamma$-Tocopherol & $0.08 \pm 0.04$ & $0.2 \pm 0.1$ & $0.07 \pm 0.03$ & $0.1 \pm 0.07$ & $<0.0001$ \\
\hline Ascorbic acid & $827.4 \pm 179.6$ & $938.8 \pm 341.5$ & $793.2 \pm 257.5$ & $849.1 \pm 272.8$ & 0.136 \\
\hline
\end{tabular}




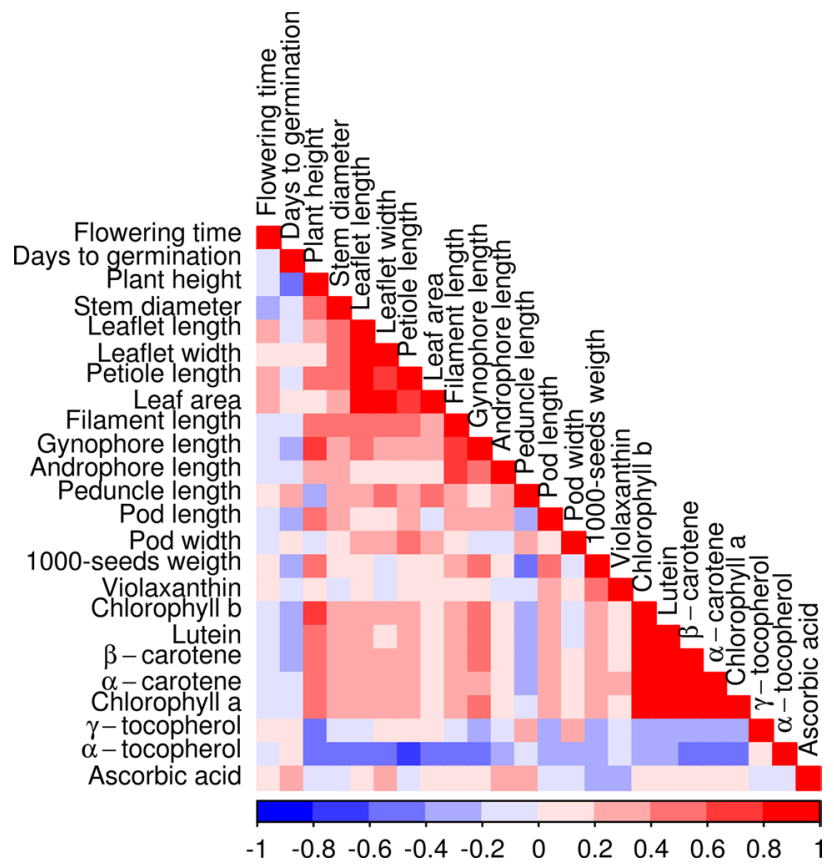

Fig. 4 Correlation plot based on Pearson's correlation between quantitative morphological descriptors and nutrient levels in 76 accessions of Gynandropsis gynandra

to elucidate the regulation of isoprenoid biosynthetic networks in the species. Another explanation could be that late flowering accessions from East Africa had higher levels of carotenoids than West African and Asian accessions which already started flowering at the time of leaf sampling. The effect of developmental stage on the levels of these compounds in the leaves should therefore be investigated. For example, Ma et al. (2016) reported a decrease in the levels of carotenoids in Chrysanthemum morifolium leaves during flower development. Tracing back the origin and colonization routes of the species could also be helpful to elucidate the differences observed in the populations from the three regions. Feodorova et al. (2010) hypothesized that the speciation event leading to G. gynandra occurred in South Africa but their sampling was limited to accessions from South Africa and Australia. The absence of correlation between Vitamin $\mathrm{C}$ and the other nutrients will facilitate breeding for high levels of both vitamin $\mathrm{C}$ and carotenoids or tocopherols in the species.

\section{Conclusion}

Our results showed that morphological traits and levels of isoprenoids (carotenoids, tocopherols and chlorophylls) analysed varied significantly among geographic regions. We also established correlations between morphological traits and the targeted nutrients. Such information is critical to design breeding programmes aiming at improving the nutritional value of the species with emphasis on pro-vitamin A, vitamins $\mathrm{C}$ and $\mathrm{E}$. The trade-off observed between carotenoids and tocopherols is reported for the first time in a plant species and requires further investigation of the genetic regulation of the biosynthetic pathways underlying these metabolites in G. gynandra. Moreover, the differences in

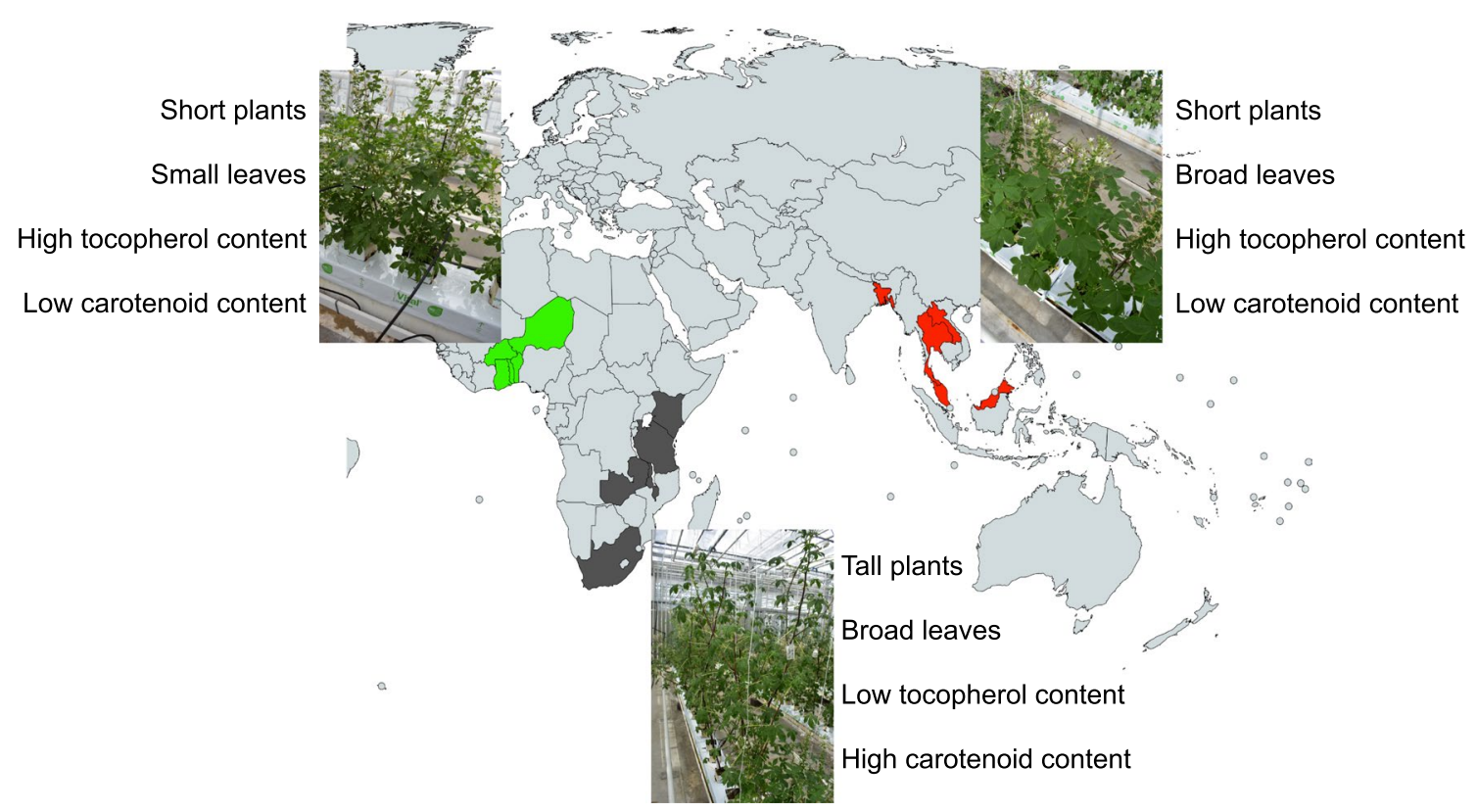

Fig. 5 Summary of main differences in morphology and nutrient content between accessions from each region. West African countries are in coloured in green, East African countries in grey and South-east Asian countries in red 
metabolic profiles across plant developmental stages should be assessed. The ninefold variation in vitamin $\mathrm{C}$ and the absence of correlation between this compound and the other nutrients specifically provides a great opportunity for breeding towards new varieties with improved nutrient compositions. Based on our results, parental lines with contrasting morphology and metabolite contents from East Africa and Asia have been selected and crossed for the development of mapping populations to accelerate breeding efforts in the species. The impact of cooking on the levels of the nutrients in the species and the potential contribution of the different compounds to recommended daily intakes should be further investigated. Moreover, we are currently analysing the variation in the metabolome of the species using a subset of 52 accessions and such information would be valuable to determine anti-nutritional factors and their potential correlation with health-promoting compounds in the species. Analysing the variation in the collection at the metabolome and the genome levels could also allow to determine whether the geographic patterns of variation observed in the collection at the morphological and biochemical levels are simply due to environmental plasticity or indeed driven by genetic differentiation due to isolation by distance.

Author contribution statement MES, RCHV and EODS conceived and designed the research. EODS and DK conducted the experiments. EGA, PM, TS and AVD contributed to the collection of plant material and phenotypic data acquisition. EODS drafted the manuscript. EGA, PM, TS, AVD and RCHV critically revised the manuscript. All authors read and approved the final version of the manuscript.

Acknowledgements We thank the Genetics and Plant Breeding Unit of the University of Ouaga 1 Prof. Joseph Ki-Zerbo for providing us with accessions from Burkina Faso; Harry Jonker and Bert Schipper for their assistance with the HPLC analyses and Maarten Peters for the greenhouse management.

Funding This study was supported by the Applied Research Fund of the Netherlands Organization for Science under the Project "Utilizing the genome of the vegetable species Cleome gynandra for the development of improved cultivars for the West and East African markets" (Project Number: W.08.270.350), the Schlumberger Foundation Faculty for the Future Fellowship awarded to E.O.D.S. and the African Orphan Crops Consortium.

\section{Compliance with ethical standards}

Conflict of interest The authors declare that they have no conflict of interest.

Open Access This article is distributed under the terms of the Creative Commons Attribution 4.0 International License (http://creativeco mmons.org/licenses/by/4.0/), which permits unrestricted use, distribution, and reproduction in any medium, provided you give appropriate credit to the original author(s) and the source, provide a link to the Creative Commons license, and indicate if changes were made.

\section{References}

Asensi-Fabado MA, Munné-Bosch S (2010) Vitamins in plants: occurrence, biosynthesis and antioxidant function. Trends Plant Sci 15:582-592. https://doi.org/10.1016/j.tplants.2010.07.003

Bellomo MG, Fallico B (2007) Anthocyanins, chlorophylls and xanthophylls in pistachio nuts (Pistacia vera) of different geographic origin. J Food Compos Anal 20:352-359. https://doi.org/10.1016/j. jfca.2006.04.002

Combs GF Jr, McClung JP (2017) The vitamins: fundamental aspects in nutrition and health, 5th edn. Elsevier, London

Cruz R, Casal S (2013) Validation of a fast and accurate chromatographic method for detailed quantification of vitamin $\mathrm{E}$ in green leafy vegetables. Food Chem 141:1175-1180. https://doi. org/10.1016/j.foodchem.2013.03.099

Cullis C, Kunert KJ (2017) Unlocking the potential of orphan legumes. J Exp Bot 68:1895-1903. https://doi.org/10.1093/jxb/erw437

da Silva GS, Canuto KM, Ribeiro PRV, de Brito ES, Nascimento MM, Zocolo GJ, Coutinho JP, de Jesus RM (2017) Chemical profiling of guarana seeds (Paullinia cupana) from different geographical origins using UPLC-QTOF-MS combined with chemometrics. Food Res Int 102:700-709. https://doi.org/10.1016/j.foodr es.2017.09.055

DellaPenna D, Pogson BJ (2006) Vitamin synthesis in plants: tocopherols and carotenoids. Annu Rev Plant Biol 57:711-738. https:// doi.org/10.1146/annurev.arplant.56.032604.144301

Feodorova TA, Voznesenskaya EV, Edwards GE, Roalson EH (2010) Biogeographic patterns of diversification and the origins of $\mathrm{C}_{4}$ in Cleome (Cleomaceae). Syst Bot 35:811-826. https://doi. org/10.1600/036364410X539880

Fiedor J, Burda K (2014) Potential role of carotenoids as antioxidants in human health and disease. Nutrients 6:466-488. https://doi. org/10.3390/nu6020466

Flyman MV, Afolayan AJ (2006) A survey of plants used as wild vegetables in four districts of Botswana. Ecology of food and nutrition 45:405-415. https://doi.org/10.1080/03670240600985431

Granado-Lorencio F, Olmedilla-Alonso B, Herrero-Barbudo C, Blanco-Navarro I, Pérez-Sacristán B, Blázquez-García S (2007) In vitro bioaccessibility of carotenoids and tocopherols from fruits and vegetables. Food Chem 102:641-648. https://doi. org/10.1016/j.foodchem.2006.05.043

Guzman I, Yousef GG, Brown AF (2012) Simultaneous extraction and quantitation of carotenoids, chlorophylls, and tocopherols in Brassica vegetables. J Agric Food Chem 60:7238-7244. https://doi. org/10.1021/jf302475d

Jiang Q (2014) Natural forms of vitamin E: metabolism, antioxidant, and anti-inflammatory activities and their role in disease prevention and therapy. Free Radic Biol Med 72:76-90. https://doi. org/10.1016/j.freeradbiomed.2014.03.035

Jiménez-Aguilar DM, Grusak MA (2015) Evaluation of minerals, phytochemical compounds and antioxidant activity of Mexican, Central American, and African green leafy vegetables. Plant Foods Hum Nutr 70:357-364. https://doi.org/10.1007/s 1113 0-015-0512-7

Kengni E, Tchouanguep MF, Mbofung CMF, Tchoundjeu Z, Asaah KE (2003) Intraspecific variation in morphological, sensory and nutritional characteristics of Dacryodes edulis fruits in West and Central Africa. Plant Genet Res 1:135-141. https://doi.org/10.1079/PGR20 03020 
Kleessen S, Antonio C, Sulpice R, Laitinen R, Fernie AR, Stitt M, Nikoloski Z (2012) Structured patterns in geographic variability of metabolic phenotypes in Arabidopsis thaliana. Nat Commun. https://doi. org/10.1038/ncomms2333

Kumssa DB, Joy EJM, Young SD, Odee DW, Ander EL, Broadley MR (2017) Variation in the mineral element concentration of Moringa oleifera Lam. and M. stenopetala (Bak. f.) Cuf.: role in human nutrition. PLoS One 12:e175503. https://doi.org/10.1371/journ al.pone. 0175503

Le S, Josse J, Husson F (2008) FactoMineR: an R package for multivariate analysis. J Stat Soft 25:1-18. https://doi.org/10.18637/ jss.v025.i01

Ma CH, Chu JZ, Shi XF, Liu CQ, Yao XQ (2016) Effects of enhanced UV-B radiation on the nutritional and active ingredient contents during the floral development of medicinal chrysanthemum. J Photochem Photobiol B 158:228-234. https://doi.org/10.1016/j.jphot obiol.2016.02.019

Masetti O, Ciampa A, Nisini L, Sequi P, Dell'Abate MT (2017) A multifactorial approach in characterizing geographical origin of Sicilian cherry tomatoes using 1H-NMR profiling. Food Res Int 100:623630. https://doi.org/10.1016/j.foodres.2017.07.059

Millett J, Foot GW, Thompson JC, Svensson BM (2018) Geographic variation in Sundew (Drosera) leaf colour: plant-plant interactions counteract expected effects of abiotic factors. J Biogeogr 45:582-592. https://doi.org/10.1111/jbi.13141

Miyazawa T, Nakagawa K, Sookwong P (2011) Health benefits of vitamin $\mathrm{E}$ in grains, cereals and green vegetables. Trends Food Sci Technol 22:651-654. https://doi.org/10.1016/j.tifs.2011.07.004

Neugart S, Baldermann S, Ngwene B, Wesonga J, Schreiner M (2017) Indigenous leafy vegetables of Eastern Africa-a source of extraordinary secondary plant metabolites. Food Res Int 100:411-422. https://doi.org/10.1016/j.foodres.2017.02.014

Odhav B, Beekrum S, Akula US, Baijnath H (2007) Preliminary assessment of nutritional value of traditional leafy vegetables in KwaZuluNatal, South Africa. J Food Compos Anal 20:430-435. https://doi. org/10.1016/j.jfca.2006.04.015

Omondi EO, Engels C, Nambafu G, Schreiner M, Neugart S, AbukutsaOnyango M, Winkelmann T (2017) Nutritional compound analysis and morphological characterization of spider plant (Cleome gynandra)—an African indigenous leafy vegetable. Food Res Int 100:284-295. https://doi.org/10.1016/j.foodres.2017.06.050

Pinela J, Carvalho AM, Ferreira ICFR (2017) Wild edible plants: nutritional and toxicological characteristics, retrieval strategies and importance for today's society. Food Chem Toxicol 110:165-188. https://doi.org/10.1016/j.fct.2017.10.020

Prunier R, Akman M, Kremer CT, Aitken N, Chuah A, Borevitz J, Holsinger KE (2017) Isolation by distance and isolation by environment contribute to population differentiation in Protea repens (Proteaceae L.), a widespread South African species. Am J Bot 104:674-684. https://doi.org/10.3732/ajb.1600232

Pucher A, Sy O, Angarawai II, Gondah J, Zangre R, Ouedraogo M, Sanogo MD, Boureima S, Hash CT, Haussmann BIG (2015) Agromorphological characterization of West and Central African pearl millet accessions. Crop Sci 55:737-748. https://doi.org/10.2135/ cropsci2014.06.0450

R Core Team (2017) R: a language and environment for statistical computing. R Foundation for Statistical Computing, Vienna

Reeves G, Singh P, Rossberg TA, Sogbohossou D, Schranz E, Hibberd J (2018) Quantitative variation within a species for traits underpinning $\mathrm{C}_{4}$ photosynthesis. Plant Physiol 177:504-512. https://doi. org/10.1104/pp.18.00168

Schönfeldt HC, Pretorius B (2011) The nutrient content of five traditional South African dark green leafy vegetables-a preliminary study. J Food Compos Anal 24:1141-1146. https://doi.org/10.1016/j. jfca.2011.04.004
Shepherd M, Savins D, Dowell A, Morrow S, Allen G, Southwell I (2017) Ecotype variation of methyl eugenol content in Tea Tree (Melaleuca alternifolia and Melaleuca linariifolia). Chem Biodiversity 14:e1700278. https://doi.org/10.1002/cbdv.201700278

Sogbohossou EOD, Achigan-Dako EG, Maundu P, Solberg S, Deguenon EMS, Mumm RH, Hale I, Van Deynze A, Schranz ME (2018) A roadmap for breeding orphan leafy vegetable species: a case study of Gynandropsis gynandra (Cleomaceae). Hortic Res 5:2. https:// doi.org/10.1038/s41438-017-0001-2

Upadhyaya HD, Reddy KN, Ahmed MI, Kumar V, Gumma MK, Ramachandran S (2017) Geographical distribution of traits and diversity in the world collection of pearl millet [Pennisetum glaucum (L.) R. Br., synonym: Cenchrus americanus (L.) Morrone] landraces conserved at the ICRISAT genebank. Genet Resour Crop Evol 64:1365-1381. https://doi.org/10.1007/s10722-016-0442-8

Usoro OB, Mousa SA (2010) Vitamin E forms in Alzheimer's disease: a review of controversial and clinical experiences. Crit Rev Food Sci Nutr 50:414-419. https://doi.org/10.1080/10408390802304222

Uusiku NP, Oelofse A, Duodu KG, Bester MJ, Faber M (2010) Nutritional value of leafy vegetables of sub-Saharan Africa and their potential contribution to human health: a review. J Food Compos Anal 23:499-509. https://doi.org/10.1016/j.jfca.2010.05.002

van den Bergh E, Külahoglu C, Bräutigam A, Hibberd JM, Weber APM, Zhu XG, Schranz ME (2014) Gene and genome duplications and the origin of $\mathrm{C}_{4}$ photosynthesis: birth of a trait in the Cleomaceae. Curr Plant Biol 1:2-9. https://doi.org/10.1016/j.cpb.2014.08.001

van Den Heever E, Venter SL (2007) Nutritional and medicinal properties of Cleome gynandra. Acta Hort 752:127-130

van Jaarsveld P, Faber M, van Heerden I, Wenhold F, Jansen van Rensburg W, van Averbeke W (2014) Nutrient content of eight African leafy vegetables and their potential contribution to dietary reference intakes. J Food Compos Anal 33:77-84. https://doi.org/10.1016/j. jfca.2013.11.003

vom Dorp K, Hölzl G, Plohmann C, Eisenhut M, Abraham M, Weber APM, Hanson AD, Dörmann P (2015) Remobilization of phytol from chlorophyll degradation is essential for tocopherol synthesis and growth of arabidopsis. Plant Cell 27:2846. https://doi. org/10.1105/tpc. 15.00395

Wahyuni Y, Ballester A-R, Sudarmonowati E, Bino RJ, Bovy AG (2011) Metabolite biodiversity in pepper (Capsicum) fruits of thirty-two diverse accessions: variation in health-related compounds and implications for breeding. Phytochemistry 72:1358-1370. https:// doi.org/10.1016/j.phytochem.2011.03.016

Weinberger K, Pichop GN (2009) Marketing of African indigenous vegetables along urban and peri-urban supply chains in sub-Saharan Africa. African indigenous vegetables in urban agriculture. Earthscan, London, pp 225-244

Wu T-H, Solberg SO, Yndgaard F, Chou Y-Y (2017) Morphological patterns in a world collection of Cleome gynandra. Genet Resour Crop Evol 65:271-283. https://doi.org/10.1007/s10722-017-0529-x

Wunnakup T, Vimolmangkang S, De-Eknamkul W (2018) Transient expression of the homogentisate phytyltransferase gene from Clitoria ternatea causes metabolic enhancement of $\alpha$-tocopherol biosynthesis and chlorophyll degradation in tomato leaves. J Plant Biochem Biotechnol 27:55-67. https://doi.org/10.1007/s13562-017-0415-9

Yang R, Keding GB (2009) Nutritional contributions of important African indigenous vegetables. African indigenous vegetables in urban agriculture. Earthscan, London, pp 105-143

Publisher's Note Springer Nature remains neutral with regard to jurisdictional claims in published maps and institutional affiliations. 